Epidemiology

\title{
Psychometric properties of the Brazilian version of the Athlete Burnout Questionnaire (ABQ) in a sample of young and adult athletes
}

\author{
Vinicius da Cruz Sousa $^{1}$ (D) , Gabriel Lucas Morais Freire ${ }^{1}$ (D), Carla Thamires Laranjeira Granja ${ }^{1}$ (D) , José Fernando \\ Vila Nova de Moraes ${ }^{1}$ (D) , Leonardo de Sousa Fortes ${ }^{2}$ (D) , José Roberto de Andrade do Nascimento Junior ${ }^{1}$ \\ ${ }^{1}$ Universidade Federal do Vale do São Francisco, Colegiado de Educação Física, Petrolina, PE, \\ Brasil; '2Universidade Federal da Paraiba, Faculdade de Educação Física, João Pessoa, PB, Brasil.
}

Associate Editor: Danilo Rodrigues Pereira da Silva. UFS, São Cristóvão, SE, Brasil.

\begin{abstract}
Aims: This study investigated the psychometric properties of the Brazilian version of the Athlete Burnout Questionnaire (ABQ). Methods: Participants were five hundred and nineteen young and adult athletes who responded to the $\mathrm{ABQ}$ and Competitive State Anxiety Inventory-2R. Data analysis was conducted through Confirmatory Factor Analysis (CFA), Cronbach's alpha, Composite reliability, average variance extracted, multigroup analysis, and Pearson's correlation $(p<0.05)$. Results: The results of the CFA confirmed the structure with three dimensions (Physical and emotional exhaustion (PEE), reduced sense of sports accomplishment (RSSA), and sports devaluation (SD) $\left[\chi^{2} / g l=2.92\right.$; $\mathrm{CFI}=.92 ; \mathrm{TLI}=.91 ; \mathrm{RMSEA}=.06]$. Internal consistency was satisfactory $(>.70)$. External validity revealed a positive correlation between PEE $(\mathrm{r}=.14)$ and $\operatorname{RSSA}(\mathrm{r}=.23)$ with somatic anxiety and a positive correlation of PEE $(\mathrm{r}=.15)$, RSSA $(\mathrm{r}=.30)$, and $\mathrm{SD}(\mathrm{r}=.14)$ with cognitive anxiety. Further, all dimensions of burnout had negative correlations with the self-confidence $(\mathrm{r}=.17-.23)$. In the factor invariance analysis, satisfactory data were found in the model's fit, establishing good factor loadings, variance/covariance, and residuals in both age groups (up to 18 years and over 18 years) and genders (men and women). Conclusion: It was concluded that the Brazilian version of the ABQ is satisfactory for the application of possible studies involving burnout syndrome in the Brazilian sports context in different group extracts.
\end{abstract}

Keywords: psychometrics; burnout; sport psychology.

\section{Introduction}

Sports participation is important for young and adult people for several reasons. Firstly, sports participation is associated with higher levels of physical activity and with the maintenance of healthy weight status ${ }^{1}$. Further, sports engagement is associated with the improvement of psychological and social outcomes, such as self-esteem, social interaction, and lower depressive symptoms in young and adult people ${ }^{1}$. On the other hand, in sports competition the athlete must be in his/her optimal performance, being physically, tactically, and technically prepared, and without being less important, being psychologically prepared ${ }^{2}$.

Psychological preparation has been highlighted in recent studies as a determinant factor to the development of the performance of competitive athletes ${ }^{3,4}$. Thus, preparation in high-performance sports demands a high training load in order to reach maximal performance ${ }^{5}$. This high stressful demand, for a prolonged period, can result in harm for the athletes, such as anxiety, depression, physical and emotional distress, and mental fatigue ${ }^{6-9}$. Such harms are directly linked to the occurrence of the burnout syndrome ${ }^{9,10}$. This syndrome can impair sports performance and the athlete's health, being the abandonment of the sports career one of the worsts consequences ${ }^{11}$.
Burnout can be defined as a multidimensional syndrome characterized by the state of emotional tension and stress provoked by distressing work conditions. According to the framework developed by Maslach et al. ${ }^{12}$, burnout can be based on three dimensions $^{6}: 1$ ) physical and emotional exhaustion (PEE), related to intense training demands and competitions for the athlete; 2 ) reduced sense of sports accomplishment (RSSA), which refers to the dissatisfaction related to the ability and achievements in the sports context; and 3) sports devaluation (SD), which represents the absence of interest and worries with the athlete's sports career.

In order to evaluate burnout, several psychometric scales have been used in the last decades, which were created according to the characteristics and the cultural contexts in which they were developed ${ }^{13}$. Among the main measures of evaluating the burnout syndrome, the Maslach Burnout Inventory (MBI) by Maslach et al. ${ }^{12}$ and the Maslach Burnout Inventory - General Survey (MBI-GS) by Cresswell ${ }^{14}$ are widely used, both being able to evaluate several aspects of burnout in human services. In the sports context, the Sports Burnout Inventory - Dual Career Form (SpBI-DC) by Sorkkila et al. ${ }^{15}$, the Athlete Burnout Scale (ABO-S) by Isoard-Gautheur et al. ${ }^{16}$ and the Athlete Burnout Questionnaire (ABQ) developed by Raedeke and Smith ${ }^{17}$ are also widely used. 
The ABQ is the most used instrument by researchers worldwide to measure the symptoms of burnout in the sports process ${ }^{17}$. The ABQ was developed based on the theory of Smith ${ }^{18}$, suggesting a relation of cause and effect, being burnout a negative effect of prolonged psychological stress. The instrument is composed of 15 items and three subscales (PEE, RSSA, and SD) which evaluate the frequency of feelings related to burnout. Studies have reported good psychometric indicators to the ABQ in several countries, such as China ${ }^{19}$, Norway ${ }^{20}, \mathrm{Spain}^{21}$, Cape Verde $^{22}$, and Mexico ${ }^{23}$.

Pires et al. ${ }^{24}$ were pioneers in translating, adapting and verifying the psychometric properties of the ABQ in Brazil, revealing acceptable psychometric properties, but with some important inconsistencies. Firstly, the authors did not perform the Confirmatory Factor Analysis (CFA) to confirm the factor structure of the instrument. Furthermore, the authors observed inconsistencies during the exploratory analysis, since three items $(3,9$, and 15) saturated in different factors when compared to the original model.

More recently, Guedes and Souza ${ }^{25}$ conducted a psychometric analysis of the Brazilian version of the ABQ with more than 1000 young athletes from the state of Paraná, verifying satisfactory results in both the internal consistency and the factorial structure of the instrument. However, the authors only evaluated youth athletes, not verifying the psychometric properties of the scale in adult athletes, which is a suggestion pointed by the authors for future researches. Moreover, the external validity of the ABQ with a correlated construct, which is an important analysis to verify if the scores of the questionnaire are correlated to other measures or backend variables ${ }^{26}$ was not performed.

Thus, these two aspects are the main differences when compared to the aim of the present study, which allows a new analysis of the psychometric properties of the ABQ with distinct particularities that are not available in the literature, since the sample of the present study is composed by both youth and adult athletes. Although there is no youth version of the ABQ, the scale has been used and has adequate internal consistency reliability among youth sport participants ${ }^{6,7}$. A sample of young and adult athletes will allow showing if the instrument is equivalent across gender and age through measurement invariance, which is an advance of this study. Jeong and Lee ${ }^{8}$ state that without establishing measurement invariance, a group comparison can be meaningless, erroneous, and nonreplicable because the differences in groups potentially do not reflect true group differences but are motivated by the different functioning of the instrument across groups. Thus, the theoretical and practical implications of a study could be limited, ambiguous, or even completely spurious for one group versus another ${ }^{6-8}$. In this perspective, the measurement invariance of the ABQ across youth and adult athletes will help researchers and practitioners to study the phenomenon of burnout among sport at different stages of life.

Considering that the analysis of the psychometric properties of the questionnaire is a continuous process that can be improved and updated in the scientific field, and considering the inconsistencies shown in previous versions of the ABQ in different languages, it is relevant that studies present more scientific evidence of this instrument which is an important tool to identify the symptoms of burnout in the sports context. Therefore, the present study aimed to analyze the psychometric properties of the ABQ with a sample of Brazilian youth and adult athletes, aiming to verify the validity of the construct (factorial structure), the internal consistency, the convergent validity, the factorial invariance, and the external validity.

\section{Methods}

\section{Participants}

In total, five hundred and nineteen youth and adult athletes who competed in the School Games of the State of Alagoas and the Brazilian College Games participated in the study. However, 11 athletes were excluded from the final sample due to not answering properly the questionnaires. As a result, 508 athletes ( 265 youth and 243 college students) aged between 11 and 42 years were included in the final sample (male $=295$, female $=$ 213 ; mean age $=18.55 \pm 4.68$ years). The sample size for CFA was determined based on the recommendations of at least 10 subjects per parameter of the model ${ }^{29}$. The athletes reported a mean time of sports practice of $72.26 \pm 66.88$ months with a mean weekly training period of $5.68 \pm 4.86$ hours. The participants represented the following sports: futsal $(\mathrm{n}=218)$, handball $(\mathrm{n}$ $=113)$, basketball $(\mathrm{n}=45)$, judo $(\mathrm{n}=34)$, volleyball $(\mathrm{n}=32)$, swimming $(\mathrm{n}=25)$, chess $(\mathrm{n}=12)$, e-sports $(\mathrm{n}=11)$, karate $(\mathrm{n}$ $=8)$, beach volleyball $(\mathrm{n}=5)$ and track and field $(\mathrm{n}=5)$.

In addition, each participant provided informed consent before participating in the study. For the athletes under 18 years of age, the parents or legal guardians signed a free informed consent term. The inclusion criteria allowed the athletes to participate in the study if they participated in sports competitions for at least six months, and were a part of one of the selected teams that participated in the study. The exclusion criterion was not to answer all the items of the instruments.

\section{Instruments}

Athlete Burnout Questionnaire (ABQ). The Brazilian version of the $\mathrm{ABQ}^{24}$ was used since it is the translation of the original instrument specially developed to evaluate the symptoms of burnout in athletes by Raedeke and Smith ${ }^{17}$. Such instrument evaluates the frequency of feelings related to burnout, being built by 15 items distributed in three dimensions: PEE (for example I am exhausted by the physical and emotional demands of the sport); RSSA (for example: no matter what I do, I don't do it as I should), and SD (for example I have negative feelings regarding sport). The instrument is answered using a likert scale from "almost never" (1) to "almost always" (5) regarding how many times the athlete has had this feeling or thought during the season. The scores of items 1 and 14 are inverted.

Competitive State Anxiety Inventory-2R (CSAI-2R). The frequency dimension of the CSAI-2R was used. This instrument 
was originally developed by Martens, Vealey, and Burton ${ }^{25}$ and validated to the Brazilian context by Fernandes, VasconcelosRaposo, and Fernandes ${ }^{26}$. It is composed of 16 items distributed in three subscales, being: cognitive anxiety (CA) (I am worried by the fact that I can lose); somatic anxiety (SA) (I feel my body tense); and self-confidence (SC) (I feel self-confident). The items are answered through a Likert type scale from "nothing" (1) to "very" (4). The results of this scale, in its adapted version, revealed a satisfactory reliability $(\alpha>0.70)$ and indexes with good adjustment $(\mathrm{CFI}=0.959 ; \mathrm{GFI}=0.942 ; \mathrm{RMSEA}=0.044)$ for the 16 items reduced model (CSAI-2R).

\section{Procedures}

Initially, the researchers contacted the competition's organizers to obtain an agreement to perform the research. Afterward, the study was approved by the local Research and Ethics Committee (protocol number 3.576.805). Data collection was performed in the hotels and/or hosting locations of the athletes/teams in the cities in which the competitions took place, during the second semester of 2019. The application of the questionnaires was performed collectively, in a private room, without the presence of the coaches, and lasted approximately 30 minutes. The order of the questionnaires was randomized among participants.

\section{Data analysis}

The descriptive analyses are presented through descriptive statistics for the continuous (mean and standard deviation) and categorical data (absolute and relative frequency). Considering that, in the literature, there were indications of consistency of the latent structure of the $\mathrm{ABQ}$ in several countries such as Norway ${ }^{20}$, China $^{27}></$ EndNote $>$, Spain ${ }^{21}$, and France ${ }^{28}$ suggesting the factorial structure supported by three latent factors (PEE, RSSA, and SD), a Confirmatory Factor Analysis (CFA) was conducted to test the psychometric properties of the instrument. The sample size of the CFA was determined based on the recommendations of at least 10 participants by parameter estimated of the mode ${ }^{29}$. In order to guarantee the adequacy of the sample, the Monte Carlo Bootstrapping technique was applied and the power of the analysis was calculated ${ }^{30}$.

The verification of the existence of outliers was performed using the square distance of Mahalanobis $\left(\mathrm{D}^{2}\right)$ since the inexistence of these cases is an assumption for this analysis ${ }^{31}$. Since normality is also an assumption for performing CFA, it was verified through studying the univariate distribution using skewness and kurtosis (ISkI $<3.0$ and $\mathrm{IKuI}<10$ ), and multivariate distribution through Mardia's coefficient for multivariate kurtosis $^{32}$. The algorithm of the maximal likelihood for estimation of the parameters was used ${ }^{32}$. Even though some authors recommend a cut-point of 0.70 as adequate for factorial loadings ${ }^{29}$, the present study opted for defining loads above 0.50 as acceptable, since such values guarantee an explained variance of the item in at least $25 \%$, and since it is also suggested by several researchers in psychometry ${ }^{31-33}$. Moreover, the Bootstrapping technique to verify the significance factorial load of each item with its respective factor was used ${ }^{30}$. In this scenario, the final model of the Brazilian version of $A B Q$ was tested using the most recommended indexes of adjustment in literature: ChiSquare ( $\chi^{2}$ and $p$-value), Root of the Mean Square Error of Approximation (RMSEA $<0.08$; C.I.90\%), Tucker Lewis Index (TLI $>0.90)$, Normalized Chi-Square $\left(\chi^{2} /\right.$ degrees of freedom, recommended between 1.0 and 3.0) and the Comparative Fit Index $(\mathrm{CFI}>0.90)^{29,31}$.

In addition, the convergent validity was analyzed (in order to verify if the items were related to their respective factors) through the calculation of the Average Variance Extracted (AVE), considering values of AVE $\geq 0.50$. Further, composite reliability (CR) and Cronbach's alpha $(\alpha)$ were calculated in order to evaluate the internal consistency of factors, adopting a cutoff point of $\geq 0.70^{29}$. In order to determine if the measurement model would be equivalent in groups with different characteristics, a multigroup analysis was conducted ${ }^{30}$. Invariance procedures suggested by Byrne ${ }^{31}$ were followed: (1) the measurement model should provide adequate fit in each sample; and, (2) configural, metric, scalar, and residual invariance criteria should be respected. A change of less than 0.01 in CFI and 0.015 in RMSEA provided evidence for metric invariance. A change of less than 0.01 in CFI and 0.015 in RMSEA provided evidence for scalar invariance ${ }^{31}$.

Lastly, to verify the assumptions of external validity of the Brazilian version of the ABQ, Pearson's correlation (r) was performed to verify the association between the dimensions of the $\mathrm{ABQ}$ and the dimensions of pre-competitive anxiety. According to the literature, anxiety can be directly linked to the physical exhaustion of the athletes, due to stressful, threatening, and challenging activities in the sports environment, which can modify the high and low levels of burnout ${ }^{35-37}$. All analyses were conducted in the software AMOS and SPSS version 22.0, adopting the level of significance of $p<0.05$.

\section{Results}

\section{Preliminary analysis}

A preliminary analysis of the data revealed that the sample had 52 multivariate outliers $\left(D^{2}=p 1<0.001\right.$; $\left.22<0.01\right)$. These participants were removed due to the possibility of compromising the internal consistency of the scale and to the fact that having no outliers is a basic assumption for the use of $\mathrm{CFA}^{38}$. The descriptive statistics of the items did not indicate deviations from univariate normality, since skewness values varied from -0.32 to 2.03 and kurtosis from -1.03 to $3.97^{38}$. However, the normalized coefficient of $\mathrm{Mardia}^{26}$ of the multivariate kurtosis $(28.36 ; \mathrm{p}<0.001)$ was above the score of 5.00, which Bentler ${ }^{37}$ suggests as an indicator of deviation from multivariate normality. Thus, the Bollen-Stine Bootstrap procedure was performed in order to obtain a corrected value of the estimated coefficients of the Chi-Square to the estimator of Maximal Likelihood ${ }^{39}$. 


\section{CFA of the Brazilian version of the $A B Q$}

Initially, a three-factor model with the 15 items (M1) was tested in order to analyze how the items would behave in their respective factors and to test a model with the same structure as the original. It was possible to notice that M1 presented a partially acceptable adjustment $\left[\chi^{2}(84)=260.76 ; \chi^{2} / \mathrm{df}=3.10\right.$; $\mathrm{CFI}=0.90 ; \mathrm{TLI}=0.88$; RMSEA $=0.07$ (0.06-0.09); $\mathrm{p}$-value $($ RMSEA $<0.05)=0.001]$ with factorial loads between 0.40 and $0.80(\mathrm{p}<0.001)$. It is worth highlighting that only items $1(0.40)$, $6(0.46)$ and $14(0.45)$ presented factorial loads below 0.50 . However, these items were maintained in the model to keep the original structure of the instrument, since factor loadings above 0.40 or close to this value, even though are not more adequate, are acceptable for the analysis of the adjustment of the model ${ }^{29}$.

Nonetheless, the indexes of modification suggested covariance between the errors of measurements of the items. Thus, a second model (M2) was tested using the covariance suggested between the errors of items 6 ("I don't worry so much regarding my sports performance as I did before") and 11 ("I am doing a lot of things that are worth in sport"), and 1 and ("I am doing interesting things in sport") and 14 ("I feel successful in sport"). Such covariances between the errors were weak $(<0.25)$ and among items of the same factors. It is possible to notice (Table 1) that the modified model with 15 items (M2) presented a satisfactory adjustment $\left[\chi^{2}(83)=242.23 ; \chi^{2} / \mathrm{df}\right.$ $=2.92 ; \mathrm{CFI}=0.92 ; \mathrm{TLI}=0.91 ; \mathrm{RMSEA}=0.06(0.05-0.07)$; p-value $(\operatorname{RMSEA}<0.05)=0.005]$.

Table 1 - Goodness-of-fit indexes of the 3-factor model of the Brazilian version of the ABQ.

\begin{tabular}{ccccccc}
\hline Model & $\chi^{2}$ & df & $\chi^{2} / d f$ & RMSEA (C.I. 95\%) & CFI & TLI \\
\hline Model 1 & $260.76^{*}$ & 87 & 3.10 & $0.07(0.06-0.09)$ & 0.90 & 0.88 \\
Model 2 & $242.23^{*}$ & 83 & 2.92 & $0.06(0.05-0.07)$ & 0.92 & 0.91 \\
Model 3 & $198.02^{*}$ & 61 & 3.25 & $0.07(0.06-0.08)$ & 0.92 & 0.90 \\
\hline
\end{tabular}

With the purpose of verifying if the items with inverted scores interfered in the adjustment of the model, a new model, without items 1 and 14, was tested. However, such a model (M3) presented similar adjustment indexes to the model with 15 items (Table 1), indicating that the model with the items with inverted scores (M2) presented better adjustment. As can be seen in Figure
1, all standardized factor loadings of the items (all statistically significant for $\mathrm{p}<0.01$ ) presented factorial validity, since the 15 items of M2 presented a factor loading between 0.40 and 0.78 . The Bootstrap replications $(\mathrm{p}<0.001)$ and the Confidence Interval (C.I. 95\%) indicated the stability of the factorial estimations and, thus, the acceptable adjustment of the model for the data.

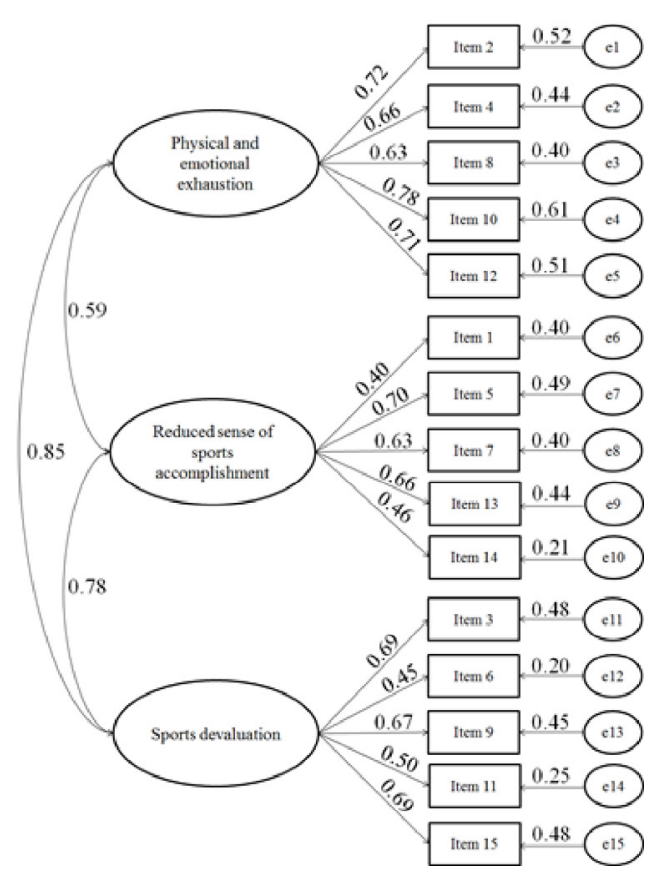

Figure 1 - Standardized coefficients of the Bootstrap replications, the correlation between factors and errors associated with each item of the modified model (M2) of the Brazilian version of the ABQ in a sample of youth and adult athletes. 
The latent factors (PEE, RSSA, and SD) of the first-order model presented moderate to strong correlations $(r>0.59)$ amongst them, suggesting the existence of a second-order factor (burnout), which was tested in model 4 (M4). Such a hierarchical model (M4) has already been tested in previous studies ${ }^{23,28}$. The indexes of the adjustment of the second-order model (M4) are identical to the indexes of adjustment of the first-order model (M2) (Table 1), supporting the hierarchical model. The factorial loads of the first-order factor to the second-order factor (burnout) were also substantially high $(\mathrm{PEE}=0.80 ; \mathrm{RSSA}=0.73 ; \mathrm{SD}=$ $0.99)$ and significant $(\mathrm{p}<0.001)$.

\section{Convergent validity and Internal Consistency}

The MEV values of the modified model (M2) with 15 items were as follows: $\mathrm{PEE}=0.50$; $\mathrm{RSSA}=0.34$; $\mathrm{SD}=0.38$. The factors for RSSA and SD presented convergent validity below the cutoff point, however, close to the recommended value $(A V E>0.50)$. The values of $C R$ were satisfactory for the evaluation of the internal consistency $(\mathrm{PEE}=0.83$; $\mathrm{RSSA}=0.71$; $\mathrm{SD}=0.75)$. The total Cronbach's alpha $(\alpha)(\alpha=0.85)$ and the values for the dimensions of the Brazilian version of the $\mathrm{ABQ}$ were satisfactory $(\mathrm{PEE}=0.81 ; \mathrm{RSSA}=0.70 ; \mathrm{SD}=0.70)$.

\section{Factorial invariance}

The factorial invariance of the factor, according to the participant's sex and age group, was investigated using multi-group analysis (Table 2), allowing us to confirm if the psychometric properties of the questionnaire did not vary for both sexes and age. Regarding sex, the multi-group analysis revealed values of $\Delta \chi^{2}$ and $\Delta C F I$ that indicate the existence of invariance between men and women in the factorial structure of the model. This was possible to infer based on the $\triangle$ CFI and $\triangle$ RMSEA between the configural, scale, and structural model $(\leq 0.01$ and $\leq 0.015$, respectively) that there was the equivalence of the intercepts of the items between groups ${ }^{40}$. Likewise, indexes suggesting a satisfactory adjustment of the models that established factor loadings, variance/covariance, and residues in both age groups (up to 18 years and above 18 years) were found.

\section{External validity}

As shown in Table 3, all dimensions of burnout presented statistically significant positive correlations $(\mathrm{p}<0.05)$ with both cognitive anxiety and somatic anxiety. Correlations varied between 0.10 and 0.30 , indicating a positive association between the dimensions (PEE, RSSA, and SD) with cognitive and somatic anxiety. Self-confidence, on the other hand, presented a statistically negative correlation $(\mathrm{p}<0.05)$ with PEE $(r=-0.19)$, RSSA $(r=-0.17)$ and $\mathrm{SD}(\mathrm{r}=-0.23)$, indicating an inverse association between the variables.

Table 2 - Goodness-of-fit indexes for the invariance of the modified model with 15 items (M2) of the Brazilian version of ABQ

\begin{tabular}{|c|c|c|c|c|c|c|c|}
\hline & $\chi^{2}$ & df & $\Delta \chi^{2}$ & $\Delta d f$ & p-value & CFI & $\Delta \mathrm{CFI}$ \\
\hline \multicolumn{8}{|l|}{ Men $v s$ Women } \\
\hline Configural invariance & 345.71 & 166 & - & - & - & 0.908 & - \\
\hline Metric invariance & 359.06 & 178 & 13.35 & 12 & 0.001 & 0.908 & 0.000 \\
\hline Scale invariance & 368.86 & 184 & 23.15 & 18 & 0.001 & 0.906 & 0.002 \\
\hline Residual invariance & 385.65 & 203 & 39.94 & 37 & 0.001 & 0.907 & 0.001 \\
\hline \multicolumn{8}{|c|}{ Up to 18 years $v s$ Above 18 years } \\
\hline Configural invariance & 308.55 & 166 & - & - & - & 0.927 & - \\
\hline Metric invariance & 318.73 & 178 & 10.18 & 12 & 0.001 & 0.928 & -0.001 \\
\hline Scale invariance & 344.99 & 184 & 36.44 & 18 & 0.001 & 0.917 & 0.010 \\
\hline Residual invariance & 364.32 & 203 & 55.77 & 37 & 0.001 & 0.917 & 0.010 \\
\hline
\end{tabular}

Note: $\chi^{2}=$ Chi-Square; $d f=$ degrees of freedom; $\Delta \chi^{2}=$ differences in Chi-Square values; $\Delta g l=$ differences in degrees of freedom; CFI = Comparative Fit Index; $\Delta C F I=$ differences in the Comparative Fit Index values; RMSEA = Root Mean Square Error of Approximation.; differences in the $\triangle R M S E A=$ differences in the Root Mean Square error of Approximation. 
Table 3 - Correlations between the dimensions of burnout and pre-competitive anxiety.

\begin{tabular}{|c|c|c|c|c|c|c|}
\hline & 1 & 2 & 3 & 4 & 5 & 6 \\
\hline 1. PEE & - & $0.35 * *$ & $0.60 * *$ & $0.15 * *$ & $0.14 * *$ & $-0.19 * *$ \\
\hline 2. RSSA & & - & $0.39 * *$ & $0.30 * *$ & $0.23 * *$ & $-0.17 * *$ \\
\hline 3. SD & & & - & $0.14 * *$ & $0.10 *$ & $-0.23 * *$ \\
\hline 4. Cognitive anxiety & & & & - & $0.58 * *$ & $-0.40 * *$ \\
\hline 5. Somatic anxiety & & & & & - & $-0.28 * *$ \\
\hline 6. Self-confidence & & & & & & - \\
\hline
\end{tabular}

\section{Discussion}

The present study aimed to analyze the psychometric properties of the Brazilian version of the ABQ in a sample of youth and adult athletes. In the present study, the validity of the construct, internal consistency, factorial invariance, and external validity were analyzed. The main results showed that the Brazilian version of the $A B Q$ presented acceptable results for the structure with three factors and 15 items. However, it is important to highlight that some inconsistencies were found and should be explored in future studies.

The analysis of the factorial structure of the ABQ revealed a model that is similar to the original one regarding its structure, with analysis being performed in order to evaluate the behavior of the items in the dimensions. The study was performed by applying four models (M1, M2, M3, and M4) in the analysis to find which one would fit best. The methods applied in the present study have also been reported in other studies ${ }^{13,23}$, proving that the procedures were performed following the main indications found in the literature.

M1 presented a partially satisfactory adjustment, however with values below the cut-point for TLI, in addition to three items with low factorial load, indicating the need to test more than one model for the study. Moreover, M1 recommended the covariance between errors of measurement of the items. The second model (M2) applied some covariance of the items found in the previous model in order to evaluate how the corrections of the items would be applied.

After establishing the covariance between the errors, the adjustment indexes of $\mathrm{M} 2$ were satisfactory regarding the athletes in the validation sample. Thus, the validity of the construct of the instrument to the Brazilian context was proved, with its main indexes above the cut-point established by literature ${ }^{29}$. Even though it was necessary to establish the covariance between the errors of measurements of the items, it is worth highlighting that these errors were weak and among items of the same factor. Therefore, the factorial validity of the model of the ABQ was not affected, since it cannot be considered as an indicator of crossed factorial loads between the items and the dimensions of the instrument ${ }^{29,39}$.
It is worth highlighting that the standardized factorial loads of the items found in the present study varied from 0.40 to 0.78 , being the items 1 ("I am doing interesting things in sport"), 6 ("I don't worry so much about my sports performance as I did before") and 14 ("I feel successful in sport") presented values below 0.50 . However, they were kept in the model (M2) since they obtained a satisfactory adjustment and their values were close to 0.50 . The values of the factorial loads are similar to the ones found in the studies performed by Guedes and Souza ${ }^{25}$ with values between 0.48 and 0.65 , and with the initial study that adapted the Brazilian version, performed by Pires et al..$^{24}$, with values between 0.52 and 0.71 . Researches about the analysis of the psychometric properties of the ABQ in other cultures also verified problems in items. The Spanish version ${ }^{21}$ indicated problems involving the nomenclature of the items of the instrument, however, different from other versions, two items (4 and 6) in the RSSA dimension, and one item (7) of the PEE dimension had terms modified in the analysis. Nonetheless, the version also presented adequate values to the literature. In the Mexican study by Martinez-Alvaredo et al..$^{23}$, the authors also observed problematic items throughout the analysis of the data, especially in item 1, which presented a factorial load below the cut-point adopted in the study. In the Brazilian context, the first study that adapted and validated the $\mathrm{ABQ}^{24}$, inconsistencies were also found in items 3 ("the effort that I need to do to practice sports could be best used in other activity"), 9 ("I'm not so interested in sport as I used to be") and 15 ("I have negative feelings regarding sport"), indicating a divergence between the dimensions of the original instrument ${ }^{17}$.

The present study also tested a model (M3) with the exclusion of the items with inverted scores (1 and 14), since evidence suggests that these items present low performance in factorial models ${ }^{41}$. Roszkowki and Soven ${ }^{17}$ suggested that items with inverted scores poorly saturate in samples of athletes. In addition, Eys, Carron, Bray, and Brawley ${ }^{41}$ suggested that a mix of items with positive and negative words could mine the psychometric properties of scales used with youth and adult athletes. Therefore, future studies should aim to correct this problem by developing and using items with only positive or negative words, as opposed to items with positive and negative 
words combined. Even though the model without the items with inverted scored (M3) presented a similar adjustment to the original model (M2), it is worth noticing that items 1 and 14 presented factorial loads below 0.50 , revealing that the original model with 15 items (M2) presented better individual adjustment and reliability of the items.

The fourth model (M4) attested the behavior of a second-order model (burnout) to verify how the latent factors appeared, similar to what was performed by Isoard-Gautheur et al. ${ }^{16}$. The weights of the second-order factors were substantially higher, showing that the second-order factor (burnout) was responsible for a high percentage of the variation of the first-order factors, and confirmed the factorial structure of the second-order model.

The coefficients of internal consistency of the present study were similar to the ones reported in the original validation ${ }^{17}$, in addition to agreeing with results reported for validations of the scale for the same construct in other contexts ${ }^{21,23,28}$. The values found for Cronbach's alpha and composite reliability in the present study were higher than the ones recommended by Nunnally $^{42}$ to demonstrate the reliability of the adequate internal consistency $(>0.70)$. It is worth highlighting that the use of composite reliability, in the present study, derives from the fact that this measure is considered a more robust indicator of precision. Since, in its equation, the factorial loads of the items are liable to variation, while in Cronbach's alpha loads of the items are fixed to be equal, as postulated by the assumption of tau-equivalence. The studies of Pires et al. ${ }^{24}$ and Guedes and Souza $^{25}$ also found similar internal consistency values to the ones of the present study.

One inconsistency found in the present study refers to the dissatisfactory values of the subscales RSSA and SD regarding convergent validity $(\mathrm{MEV}<0.50)$, indicating a limitation towards the convergent validity of the factors of the first order. This should be explored in future studies. Valentini, Oliveira, and Damasio ${ }^{45}$ stated that MEV values suffer modifications due to the number of items and the homogeneity of the factorial loads, in a way that adopting fixed cut points could limit the interpretation of the findings ${ }^{44}$.

The adequacy of the model proposed for the Brazilian version of the ABQ was also evidenced in the analysis of invariance considering sex (men vs women) and age group (up to 18 years $v s$ above 18 years). The results indicated a configurational and metric invariance between men and women and youth and adults. This proves that the scale is versatile to be used in groups of male and female athletes. These results confirm what is already available in the literature, supporting the validity of the construct regarding the invariance by sex and age ${ }^{22}$. Such finding indicates that despite the inconsistencies found in the latest model, the Brazilian version of the ABQ is versatile to be used in groups of youth and adult athletes, male and female, indicating that the proposed structure - same items being explained by the same latent variables - are maintained in different sexes and ages ${ }^{34}$ and that the residuals of the items are the same for both groups ${ }^{33}$. Guedes and Souza ${ }^{25}$ also evaluated the invariance of ABQ with youth Brazilian athletes, verifying a satisfactory adjustment for both sexes and the different ages of the athletes $(<14$ years, 15 to 16 years, and 17 years).
The external validity was verified by the correlation between the subscales of the ABQ and the dimensions of pre-competitive anxiety since pre-competitive anxiety is associated with the physical and emotional exhaustion of the athlete, to the point in which the higher are the stressing agents faced, the higher is the distress $(16,42)$. The results indicated that all the dimensions of burnout (PEE, RSSA, and SD) presented a positive association with somatic anxiety (physiological responses) and cognitive anxiety (emotional factors). Therefore, it is possible to notice that the negative and destructive thoughts, and the physiological reactions that derive from such thoughts, are associated with the increase of the symptoms of burnout. Gomes et al. ${ }^{34}$ pointed to a direct relationship between burnout and anxiety in the sports context, evidencing that the more the athlete experiences a high perception of threats associated with a low perception of challenge, the higher are the levels of burnout. Another important finding was the inverse association between the dimensions of burnout and self-confidence, an indication that feeling the confidence to execute the tasks could be considered a protective factor for the symptoms of burnout ${ }^{44,45}$. The present study's results were similar to the ones found in a study with Chinese Kung $\mathrm{Fu}$ athletes ${ }^{44}$, suggesting that the higher the levels of self-confidence, the lower are the indications of burnout, as found in literature ${ }^{10,43}$. Such results are relevant, considering that the previous studies that analyzed the psychometric properties of the ABQ in Brazil ${ }^{12,24}$ did not analyze the external aspect of the validity of the construct.

The present study has some limitations that should be considered. First, only 11 different sports were included and some of them had a low number of participants (for instance, karate, beach volley, and track and field). Therefore, future studies should evaluate a higher number of participants and a higher variety of sports. A second limitation is the lower number of athletes from individual sports, revealing the need for future studies about the factorial structure of the $\mathrm{ABQ}$ in higher samples of these modalities. Another aspect that future studies should evaluate is if the grouping of individuals in the teams affects the results of the factorial validity tests and other psychometric tests using the scale. Also, predicting variables and criteria were measured at the same time, which can lead to measuring biases ${ }^{29}$. Even though there was an attempt to eliminate bias, by performing an anonymous study using instruments that are well established in the literature, future studies should use different research models, such as a longitudinal approach, in order to establish the predictive validity of the ABQ. Finally, one other limitation of the present study is that only certain elements of the validity of the construct were tested. Thus, future studies should aim to evaluate additional aspects of the validity of the construct.

In a general way, the positive findings of the present study regarding the Brazilian version of the ABQ are the important discovery of more evidence regarding an internationally known instrument to measure burnout symptoms. The ABQ allows professionals and researchers to precisely evaluate the main symptoms of burnout in Brazilian youth and adult athletes.

Specifically, the ABQ can provide relevant information to aid sports psychologists and coaches to better understand the appearance of symptoms of burnout among athletes, allowing the 
practitioners to comprehend different dimensions and potentially set parameters to psychological preparation in the sports context. Moreover, Brazilian researchers will be able to use the scale to investigate theories that could help explain the mechanisms by which youth athletes develop symptoms of burnout throughout their sports practice.

\section{References}

1. Drake KM, Beach ML, Longacre MR, MacKenzie T, Titus LJ, Rundle AG, et al. Influence of sports, physical education, and active commuting to school on adolescent weight status. Pedi. 2012;130(2):e296-304.

2. Baker J, Cobley S, Schorer J, Wattie N. Talent identification and development in the sport. Routledge handbook of talent identification and development in sport. 2017:1-8.

3. Schinke RJ, Stambulova NB, Si G, Moore Z. International society of sport psychology position stand: Athletes' mental health, performance, and development. Int J Sport Exercise Psy. 2018;16(6):622-39.

4. Fortes LS, Lima-Junior D, Nascimento-Júnior JR, Costa EC, Matta MO, Ferreira ME. Effect of exposure time to smartphone apps on passing decision-making in male soccer athletes. Psychol Sport Exerc. 2019;44:35-41.

5. Loturco I, Contreras B, Kobal R, Fernandes V, Moura N, Siqueira $\mathrm{F}$, et al. Vertically and horizontally directed muscle power exercises: Relationships with top-level sprint performance. PloS one. 2018;13(7):e0201475.

6. Gustafsson H, Lundkvist E, Podlog L, Lundqvist C. Conceptual confusion and potential advances in athlete burnout research. Percept Mot Skills. 2016;123(3):784-91.

7. Li C, Wang CJ, Kee YH. Burnout and its relations with basic psychological needs and motivation among athletes: A systematic review and meta-analysis. Psychol Sport Exerc. 2013;14(5):692-700.

8. Martínez-Alvarado JR, Guillén García F, Feltz D. Athletes' motivational needs regarding burnout and engagement. Rev Psico Deporte. 2016;25(1):65-71.

9. Pires DA, Ferreira RW, de Vasconcelos ÂSB, Penna EM. Dimensões de Burnout, Estratégias de Coping e Tempo de Prática como Atleta Federado em Jogadores Profissionais de Futebol. Cuad Psico Deporte. 2019;19(2):175-85.

10. Gustafsson H, DeFreese J, Madigan DJ. Athlete burnout: Review and recommendations. Curr Opin Psychol. 2017;16:109-13.

11. García-Parra N, González J, de los Fayos EG. Estado actual del estudio del síndrome de burnout en el deporte. Cua Psico Deporte. 2016;16(2):21-8.

12. Maslach C, Jackson SE, Leiter MP, Schaufeli WB, Schwab RL, Editors. Maslach burnout inventory. Ed. Consulting psychologists press, Palo Alto, CA, 1986.

13. Guedes DP, Souza ROd. Psychometric properties of the Athlete Burnout Questionnaire for young Brazilian athletes. J Phys Educ. 2016;27.

14. Cresswell SL, Eklund RC. The convergent and discriminant validity of burnout measures in sport: A multi-trait/multi-method analysis. J. Sports Sci. 2006;24(2):209-20.
15. Sorkkila M, Ryba TV, Aunola K, Selänne H, Salmela-Aro K. Sport burnout inventory-Dual career form for student-athletes: Assessing validity and reliability in a Finnish sample of adolescent athletes. J Sport Health Sci. 2017.

16. Isoard-Gautheur S, Martinent G, Guillet-Descas E, Trouilloud D, Cece V, Mette A. Development and evaluation of the psychometric properties of a new measure of athlete burnout: The Athlete Burnout Scale. Int. J Stress Manag. 2018;25(S1):108-23.

17. Raedeke TD, Smith AL. Development and preliminary validation of an athlete burnout measure. J Sport Exercise Psy. 2001;23(4):281-306.

18. Smith RE. Toward a cognitive-affective model of athletic burnout. J Sport Exercise Psy. 1986;8(1):36-50.

19. Lu J, Chen L, Cho K. Revision of Raedeke and Smith's Athlete Burnout Questionnaire (ABQ): Analyses of validity and reliability of Chinese version. J. Phys. Educ. 2006;39(3):83-94.

20. Lemyre P-N, Roberts GC, Stray-Gundersen J. Motivation, overtraining, and burnout: Can self-determined motivation predict overtraining and burnout in elite athletes? Eur J Sport Sci. 2007;7(2):115-26.

21. Arce C, De Francisco C, Andrade E, Seoane G, Raedeke T. Adaptation of the Athlete Burnout Questionnaire in a Spanish sample of athletes. Span J Psychol. 2012;15(3):1529.

22. De Francisco C, Lopes-Furtado E, Arce C. Adaptação do ABQ para a medida do burnout em jovens jogadores de futebol caboverdianos. Rev Psico Deporte. 2018;27(1):77-86.

23. Martínez-Alvarado JR, Guillén F, Aguiar-Palacios LH, Magallanes AG, Fernández-Ruíz P, Asadi AA. Analysis of the psychometric properties of the athlete Burnout Questionnaire (ABQ) in Mexican athletes. Anal Psico. 2019;35(2):314-22.

24. Pires DA, Brandão MRF, da Silva CB. Validação do questionário de burnout para atletas. J. Phys. Educ. 2006;17(1):27-36.

25. Martens R, Vealey RS, Burton D. Editors. Competitive anxiety in sport. Ed. Human kinetics, Illinois, 1990.

26. Fernandes MG, Vasconcelos-Raposo J, Fernandes HM. Propriedades psicométricas do CSAI-2 em atletas brasileiros. Psico Refl Crí. 2012;25(4):679-87.

27. Chen FF, Sousa KH, West SG. Teacher's corner: Testing measurement invariance of second-order factor models. Structural equation modeling. 2005;12(3):471-92.

28. Isoard-Gautheur S, Oger M, Guillet E, Martin-Krumm C. Validation of a French Version of the Athlete Burnout Questionnaire (ABQ). Eur J Psychol Assess. 2010;26(3):203-11.

29. Hair JF, Risher JJ, Sarstedt M, Ringle CM. When to use and how to report the results of PLS-SEM. Eur Bus Rev. 2019; $1: 2-24$.

30. Sass DA. Testing measurement invariance and comparing latent factor means within a confirmatory factor analysis framework. J Psychoeduc Assess. 2011;29(4):347-63.

31. Brown TA. Editor. Confirmatory factor analysis for applied research. Ed. NY:Guilford Press, New York, 2012.

32. MacCallum RC, Browne MW, Sugawara HM. Power analysis and determination of sample size for covariance structure modeling. Psychol Methods. 1996;1(2):130.

33. Byrne BM. Editor. Structural equation modeling with LISREL, PRELIS, and SIMPLIS: Basic concepts, applications, and programming, Ed. Psychplpgy Press, New York, 2013. 
34. Kline RB, Assumptions in structural equation modeling. In: Handbook of structural equation modeling, R. H. Hoyle (Ed.), Ed. The Guilford Press, 2012.

35. Brown TA. Editor. Confirmatory factor analysis for applied research. Ed. Guilford publications, New York, 2015.

36. Vealey RS, Armstrong L, Comar W, Greenleaf CA. Influence of perceived coaching behaviors on burnout and competitive anxiety in female college athletes. J Appl Sport Psychol. 1998;10(2):297-318.

37. Cho S, Choi H, Kim Y. The Relationship between Perceived Coaching Behaviors, Competitive Trait Anxiety, and Athlete Burnout: A Cross-Sectional Study. Int J Env Res Pub Health. 2019;16(8):1424.

38. Haghighi M, Gerber M. Does mental toughness buffer the relationship between perceived stress, depression, burnout, anxiety, and sleep? Int J Stress Manag. 2019;26(3):297-305.

39. Hair Jr JF, Sarstedt M, Hopkins L, Kuppelwieser VG. Partial least squares structural equation modeling (PLS-SEM). Eur Bus Rev. 2014;26(2):106-21.

40. Marôco J. Editor. Análise de equações estruturais: Fundamentos teóricos, software e aplicações. Ed. Report Number, Lda, Portugal, 2010.

41. Wang S, Chen C-C, Dai C-L, Richardson GB. A call for, and beginner's guide to, measurement invariance testing in evolutionary psychology. Evol Psychol Sci. 2018;4(2):166-78.

42. Woods CM. Careless responding to reverse-worded items: Implications for confirmatory factor analysis. J Psychopathol Behav Assess.2006;28(3):186.

43. Nunnally JC. Psychometric theory 3E: Tata McGraw-hill education; 1994.
44. Silva ASR. Burnout, ansiedade e depressão em atletas: adaptação do Athlete Burnout Questionnaire. Porto. Dissertação [Mestrado Integrado em Psicologia, área de Psicologia das Organizações, Social e do Trabalho] - Universidade do Porto, 2016.

45. Mehrsafar AH, Hemayat TR, Khabiri M. The Role of Competitive Anxiety and Self-Confidence in Prediction of Burnout in Elite Wushu Athletes1. Sport Psychol studies. 2018; 7(23):35-50.

46. Cremades JG, Wated G, Wiggins MS. Multiplicative measurements of a trait anxiety scale as predictors of burnout. Meas Phys Educ Exerc Sci. 2011;15(3):220-33.

\section{Corresponding author}

Gabriel Lucas Morais Freire. Universidade Federal do Vale do São Francisco. Avenida José de Sá Maniçoba, Petrolina, Pernambuco, 56304-917. Telephone: +55 (87) 2101-6851

Email: bi88el@gmail.com

Manuscript received on July 27, 2020

Manuscript accepted on November 12, 2020

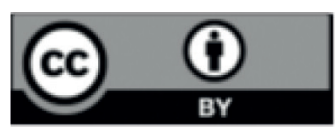

Motriz. The Journal of Physical Education. UNESP. Rio Claro, SP, Brazil - eISSN: 1980-6574 - under a license Creative Commons - Version 4.0 